\title{
Information Technology and the Digital Economy
}

\author{
Afërdita Berisha-Shaqiri \\ Mihane Berisha-Namani
}

Faculty of Economics, University "Hasan Prishtina", Kosova

Doi:10.5901/mjss.2015.v6n6p78

\begin{abstract}
Information technology and digital economy present new opportunities for all sectors of the economy. Today, economy is undergoing fundamental changes as a result of the rapid development of information technology and its use is also very fast. Especially the dynamics of the development of informatics and its products and business development opportunities based on the use of Internet technology have enabled the growth of the role and importance of using information technology in business processes in terms of the new economy or digital economy. The world economy has changed due to the great development and application of this technology. Enterprises are forced to survive in a modern economy where the global market is characterized by competition, diversity of products and services and short cycle life of the product. In terms of the digital economy, information technology creates opportunities for specialization and cooperation between companies from different regions by reducing transaction costs, creating ease of access to foreign markets and facilitating the development of new models of electronic business. The purpose of this paper is to present the importance of information technology in economy, computerization trends and the opportunities offered by this technology where consumers have quick and easy access on the global market, as well as in information about goods and services. In the condition of digital economy the usage of information technology provide businesess with new opportunities to access global markets and also develop business activities on-line. The full realization of these potentials is essential for new enterprises and companies which can compete and create competitive advantage globaly.
\end{abstract}

Keywords: information technology, digital economy, market, business, competition.

\section{Introduction}

Digital economy has a significant implication in business transformation and creation of new digital businesses. Moreover digital economy offers great opportunities for small and medium enterprisess. However, this does not mean that they will definitely have success in the new conditions and electronic market. We should emphases that the growth of the digital economy means that computers operate in conditions of constant and global competition.

The best way to be safe and to avoid possible errors in this direction is to understand the interrelationship between business risks and opportunities that information technology offers (Berisha-Namani, 2004,183-192). An example is Amazon.com's digital company which in 1996 brought business in computer networks or the Net, where companies presenting catalogs as brochures, orders received, make payments, accept returns of assist the customers to process business transactions through the Internet. In other words, Amazon provides an example of an electronic market to a private enterprise. Therefore, economically can be explained that the investment in information technology infrastructure almost always turn to increased productivity and profitability of the enterprise.

Using information and communication technology (ICT) contributes significantly to the growth and development, because it raises productivity and work efficiency by enabling creativity and stimulate innovation, and most importantly helps the penetration and the existence in global markets. ICT enables the participation of all stakeholders in the programs and projects regardless of their location and physical distance, if available and have access to the network infrastructure of ICT.

Enterprises are often motivated to apply IT in business processes, if it is necessary in internal business processes for better quality information or even the impact on competition. Business processes are a series of activities that transform inputs into outputs, goods, and services.

Enterprises are required to improve business processes to stay competitive in today's market. During the last 1015 years, companies have been forced to improve their business processes, because we, as clients are demanding products and services better. And if we do not get what we want from a supplier, we have many to choose from other business competitors. Therefore, many companies begin the process of improving business performance with a 
continuous improvement model. This model made efforts to understand and measure the actual business process and its performance accordingly. This method for improving business processes is effective. However, during the last 10 years, several factors have accelerated the need to improve business processes with the most appropriate method. Internet technology and its use of which has rapidly increased competition, the opening of global markets and creating opportunities for free trade has extended enterprises make changes in performance and speed of introduction in the market with products and services.

The aim of this paper is to present the importance of electronic business, computerization trends which has changed the economy, society and politics. This is the main reason why enterprises today in tighter competition are orientated towards the market and to fill up the requirements of the buyers. So, the aim is to describe digital economy, opportunities of Internet usage for business to achieve strategic advantages compared to their competition and how can facilitate the movement of goods and services from producers to customers.

\section{Definition of the Economy Computerization and Digitalisation}

The beginning of the 21st century has seen a rapid change from the industrial economy to a digital economy built on computers, connectivity, and human knowledge by (McKeown, 2009). In the world of free trade where competition grows speed is vital for each sector if the use of information technology in the production process, management or other business processes. Since the business environment is constantly changing and evolving, the business itself changes all the time and with the growth and development information needs to ask businesses will vary. At the same time information technology and computing system needs to support growth, change and development. (Vakola and Wilson, 2004, 112-120). Information Technology has influence on changing the society, economy and business. Computing system linking subsystems and presents information in a unique way while business conceptual structure aims computerization of processes in the enterprise.

Our study shows that economy has moved to digitalization and usage of information technology becoma important, if not the most important resource for economic development of a country. Furthermore, the usage of information technology are regarded as primary source of competitive adventage for any enterprises which have become to understand the importance of this technology as an enabler of social and economic development.

Computerization of the economy effectively integrates the organization of employees, management, technology for the flow of information, materials, and funding in the ongoing effort to produce high quality and low price and excellent service and clean environment.

The emergence of the digital economy presents new opportunities for all sectors of the economy to computerized and be competitive. In this economy, customers provide quick access and easy on the global market as well as information concerning the place where competing goods and services. Businesses provide opportunities for access to the global market and also develop business activities on-line. The full realization of these potentials digital economy is essential for enterprises and companies, and industries of different countries.

The new economy has to do entirely with the competition for the future, the capacity to create new products or services with high quality and less cost and with the ability to transform businesses into entities that can not be imagined yesterday that tomorrow may be obsolete. Digitization of new products and services, electronic business and electronic payments are the key of success. While the old economy was based on: iron, brass, stainless steel and analog and physical sizes. New economy based on: silicon, computer, information networks considering how creative economic value. In this economy, information is presented in digital form and in the form of binary code $(0,1),($ Mustafa, M.,2010), and business processes are transformed from the physical reality on digital reality based on Bits. (Berisha-Namani, M., 2010, 53).

Information technology is built around the chip and in terms of the digital economy information technology opens possibilities for specialization and cooperation between companies from different regions also reduces transaction costs in business cooperation, provides access to foreign markets and ensures that different companies may specialize in products various digital and cooperate by exchanging digital products between companies of different regions depending on customer demand. This collaboration facilitates the development of small and medium ${ }^{1}$ as well as electronic access to these markets and the development of new forms and models of business as business, or electronic business.

There is no comprehensive definition associated with the computerization of the economy. In general, the informatization of the economy means the utilization of Information and Communication Technology (ICT) and the use of

1 These companies will employ a small number of workers and to specialize in a certain number of digital products (software preparing a bookkeeper or different educational programs, ticket sales agencies for digital roads etc.) 
modern methods of management to optimize the life cycle of products, including market demand analysis, product definition, research and development, design services, environmental protection and other issues.

Information Technology and the Internet ${ }^{2}$ provide the opportunity to buy anything ranging from books and other items different because countless web pages advertise products and services on various emails that offer buying and selling these products. Therefore the development of rapid and fast this technology, electronics business development, increasing demand for accurate and relevant information on time and increasing large number of users have contributed to the computerization of the economy to be of great importance for the development and enhancing the competitiveness of the economy of various countries.

\section{Information Technology Trends}

Information technology is being used in all spheres of social and economic life, especially in manufacturing, scientific and business transactions, management and service activities for performing different. Businesses have realized that without information there is no successful business and this is why ICT technology finds application today so great.

Increase productivity and reduce costs in developed countries rely on computer running production in robotization of production, the rapid growth of microelectronics manufacturing equipment and computerization of administrative affairs (Mustafa M, 1995, 254).

Today, thanks to major investments made in these areas in the most developed countries of the world of microelectronics production equipment increased by an annual rate of 20\%,25\% robots, complex technology and CAD I CAM for $30 \%$. Continuously falling prices of their modules and this greatly affects the growth of the level of computerization.

The most important trends in technology which increase the level of computerization according to (Keneneth C. Laudon, Jane P. Laudon, 2000, 184), are:

- Use increasingly large digital signals as opposed to analogue ones, ${ }^{3}$ as well as the trend of computerization of all life processes.

- Moving from technology based on counties with semi conductors elements in circles with chip, has enabled the refinement of communication and digitization creating conditions that many economic activities they imagined replaced by virtual. 4 Virtualization enables and enhances the flexibility of the technologies are enabling companies to consolidate their technological infrastructure in order to decrease your administrative and maintenance costs and to prepare for new strategic initiatives, by (Turban, E., Volonino, L., Wood, G., 2013.67)

- Integration into computer networks is undoubtedly characteristic of the new economy. Operation of electronic markets has changed the structure of the economy. Large multinational companies need to apply for a new strategy which is the result of the convergence between computing, communications and relaxation, because the content of knowledge in the product is growing and getting more information in digital form and memorized in computer.

- The new economy based on innovation because to exist on the market must have innovative skills. Therefore, due to this and other trends a large number of employees have access to innovative work.

- Passing of information systems based on a central computer in the client-server systems that enable massive data processing, graphics, guidance systems, multimedia etc.

- Interaction of multimedia which is defined as technology that helped or integrated by two or more types of media such as text, graphics, voice, with all kinds of video or other animation techniques based on computer applications. Multimedia has become the basis for creating new products and services such as electronic books, newspapers, electronic classroom presentation technology, images, graphic designer tools and voicemail videos etc.

- Processing of data by processing specific multimedia processing, and today most web sites use multimedia.

- Another important trend in information technology is the transition to open systems computing where only

\footnotetext{
2 Well Internet changing the way business leadership made the leader in Internet research company Forrester Research such as (USA), to find information on how e-companies among themselves through e-commerce transactions are conducted in the amount of 43 billion US \$ in 1998. in 2003 this amount was expected to reach the value to 1.3 trillion US \$. Although this amount represents only a small part of the overall transaction but with a constant tendency to increase with greater.

${ }^{3}$ Passing and massive conversion of analogue to digital equipment: TV, radio, discs, telephones etc.

${ }^{4}$ Virtual Office enables businessmen from home via computer and communications network to perform works with high efficiency.
} 
these systems will be present and competing before users and buyers, because the connection of systems in local and global networks and increase the opening of the entire application system.

From the above trends is considered the most important use of the internet which has its beginnings in the Arpanet network and global computer networks that are presented in the late 60s of the twentieth century (more precisely in 1968), according to (Berisha M. 2002.156). Internet usage is growing faster than any other technology in the history of development of human society. Between 1993 and 1997, the number of computers connected to the Internet has increased from 1 million to 20 million. In 2001 this number was 250 million, the trend today is steadily growing.

So the result of all these trends is the so-called information superhighway (ICT), which is the centerpiece of the digital economy and the network intelligence. Based on the model of the Internet, the information superhighway is being turned into a wide network interconnection systems or web communication, which can absorb large amounts of voice, text, and photos for thousands of users in homes, schools, businesses, etc.. So telecommunication technology enables as noted above a disposable mesh of all, by virtue of all the computers in the world can relate to communicate with each other through various applications in an interactive and multimedia form under according (Timothy J.O ' Leary \& Linda I.O'Leary, (1997-98).

The benefits of information technology trends mostly seen in:

- Reducing the cost of production, travel, materials, marketing and distribution;

- Increase the value chain management and improving internal functioning;

- Construction of the markets and more advanced service to customers;

- Gaining competitive skills and speed when performing transactions;

Considered future trends in computerization would say fast chip, package and large amount of computational power in very small spaces. Micro will embed artificial intelligence in all everyday devices, including smart cards (smart carts). The computers will be used more widely, and computers associated with information technology will be able to integrate and process the data, images and voice by (Keneneth C. Laudon, Jane P. Laudon, 2000,188).

\section{Electronic Business}

Information technology trends are one of the relevant factors which today are helping businesses to penetrate new markets for being innovative and producing new products and services. Therefore, with full right, we can conclude that the role of information technology in the manufacture of new products and services is enormous. If an enterprise does adequately identify the information technology for its competitive business market by providing appropriate software, it will be able to perform the organization and accumulation of data and information necessary and timely to develop new products and services.

Electronic business via electronic mail, voice mail, videoconferencing, data conference, teleconferencing and electronic exchange of data enable the internet connection which gave a new boom in sharply changing market, economy, society and politics by changing products, services, consumer behavior, etc. At the same time, the rules of European and national competition will be implemented to ensure that small businesses to have all opportunities to enter new markets and compete on fair terms, etc. (European Commission, 2000).

Electronic business means according (Beqiri E, 2013,40):

- optimizing business processes (production, marketing, distribution, sales, payments, etc.).

- improving relations (with the public, customer, supplier, distributor, etc.).

- improving business services (banks, agencies, advocacy, accounting, etc.).

Key elements of the surroundings that electronic business practices are: global infrastructure, links to suppliers, links with buyers and clients and links with intermediary. So, being connected to the internet, companies have the opportunity to do research faster, build websites that promote their products, to monitor consumer behavior and to develop video conferencing. It is worth to mention one of the most revolutionary developments in advanced communication technologies, such as voice over internet protocol (VoIP), which includes all types of voice communication transmitted through the internet, between the computer with the computer or in hybrid form between PC and regular phone. Advanced computer technology is sophisticated, though it is often very expensive and takes more time to be implemented by an enterprise.

\section{Manifestations of Computerization in Economy}

The rapid and rapid information technology has influenced informatics have an important role in business development. Manifestations of computerization in the current economy mostly reflected in the application of information systems for 
planning and strategic analysis different, especially when making long-term decisions. These systems consist of several information systems and management control systems for decision support. By The construction of these systems was originally a requirement for strategic planning of Top managers (the highest level of leadership) and had primary goal easier access to important information, especially those that were classified as information and critical factor to success the enterprise. (David L.Anderson ,2000, 292 ).

While information technology and the Internet now increasingly as a basis for new business models in different business processes known as electronic business. Electronic businessas as illustrated above is something more than selling and buying products through the Internet which also included customer service, cooperation with other business partners and distribution and supply. While e-commerce is also an internet business as e-business, but that is a part of it. E-commerce is focused only on buying and selling products and services online. These two concepts are used as synonymous with one another, so even today most people use the term e-commerce instead of the term e-business.

We can say that information technology and knowledge-based economy are producing different products and services in unpredictable values, mention electronic business forms: electronic market; electronic marketing; electronic scholarships; electronic banking transactions; electronic distribution of knowledge and services etc. While e-business models are classified into the following categories:

1) business - to - business (business-to-business) or B2B

2) business - to - customer (business-to-costumers) or B2C

3) the customer - to - business (costumers-to-business) or $\mathrm{C} 2 \mathrm{~B}$

4) customer - to - customer (costumers-to-costumers) or C2C

As regards the use of information technology for business purposes in our country and the manifestation of computerization in the economy in early 2005 New Bank of Kosovo, has started with the delivery of e-banking service for Kosovar businesses. This is made possible on-line access to a bank account and payments over the Internet. Currently offered only payment services within the bank is bill payment of energy spent, payment of water bills and some payments for the extraction of various documents. Since 2005, ProCredit Bank, started with e-banking services for Kosovar businesses. On-line payments, are offered by Raiffeisen Bank too which provide payment services in trade shops through bank cards and POS terminals. Also, these two banks have also developed network of ATM machines to withdraw the Resi-operation with international bank cards VISA and MasterCard. ${ }^{5}$

All these have made possible in large measure e-business development, transformation and increased productivity. Also, the communications through the Internet within a company (intranet) or between companies and consumers can help reduce delays in the supply chain. Electronic commerce offers the following options such as: Improving the credibility to set better image and the trend; Promotion of products or services; advertising in more markets and lower costs; answer the questions about products or services; submission of bids directly from the computer ("online"); reduce the response time to customer requirements; access to customer feedback; improve customer service; possibility of providing the services non-stop 24 hours a day; using e-mail as a tool for marketing (marketing), the use of e-mail as a means of communication with customers; provision of documents in electronic form (without paper); operation with net dilerve more efficiently; possibility of external market research etc.

Research shows that in the near future, the distribution of industrial innovation more people will be much faster than in the past. Global markets on the Internet will provide new opportunities for small traders in the developed and developing world, but also the global competition could easily seep into small local markets. Businesses big and famous names dominate the Internet while smaller ones have enough participation in e-commerce, although the benefits are evident.

Economic effects manifested through computerization of Kosova economy are: competitive advantages express digital economy as growth in productivity, reduction of the spending, resource saving, energy saving and environmental protection of life, hence the competitiveness of economy in the world market depends most on the level of computerization of the economy. Organizations, institutions and different subjects use this technology for electronic data processing in their work, communication, inter-nanowire with units internal and external including cooperation between by buyers, suppliers, other mechanisms and institutions around the world for over twenty-four hours a day.

As we can see, this is a challenge for many businesses, which raise the need for usage of advanced information technology and information systems, which will be able, to cope with success, various provocations in competitive environment.

${ }^{5} \mathrm{MTI} \mathrm{KS}$, report on the implementation of the European Charter of Small Enterprises in Kosovo, the European Charter for Small Enterprises, Questionnaire 2005. 


\section{Conclusion}

To achieve economic and social development, as well as higher standards of living should be paid special attention to information society development, use and spread of information technology in all business activities. That businesses be successful it is vital the use of new technologies. ICT and e-business constantly being advanced is helping businesses to compete in the global market. Information technology creates opportunities for increased efficiency and flexibility of business processes and collaboration in the group. All successful companies are using this technology and are creating entirely new business and competitive advantage.

We should be realistic and accept that electronic business opens the way to become part of global business processes to cope with international competition, therefore, the importance of digitizing becomes inevitable because of this technology depends on the growth of competitiveness in global scope. The global nature of the digital economy will limit the capacity of the national economy. It should therefore work in this direction in order to be absorbed benefits that brings the digital economy.

Computerization of the economy which is expressed in the electronic commerce will become the main element in the future of the global economy. In years to come it will increase efficiency to do business "on line" that means the performance of all business activities (purchases, sales and other associated transactions) by electronic means.

\section{References}

Berisha-Namani, M.: (2004), Informatika e biznesit, Prishtinë

Berisha-Namani, M.:(2011), Biznesi elektronik, Prishtinë.

Beqiri E,: (2013),Informatike biznesi me biznes elektronike, Pejë

David L.Anderson: (2000) Managing Information Systems, 1st Edition, Prentice Hall.

European Commission.: (2004). Education for entrepreneurship: Making progress in promoting entrepreneurial attitudes and skills through primary and secondary education. Retrieved from http://europa.eu.int/comm/enterprise/enterprise_policy/charter

Keneneth C. Laudon, Jane P. Laudon, (2000), Management information systems, sixth edition, Organization and technology in the networked enterprise.

McKeown, P. : (2009): Information Technology and the Networked Economy, Global Text, Zyrich, Switzerland.

MTI KS, report on the implementation of the European Charter of Small Enterprises in Kosovo, the European Charter for Small Enterprises, Questionnaire 2005.

Mustafa M.,(1995) Kibernetike dhe hyrje ne informatike.

Mustafa, M., Sistemi informatik i menaxhmentit, ligjëratate autorizuara, viti shkollor 2009/2010.

Timothy J.O'Leary \& Linda I.O'Leary , (1997/98)Computing Essentials, McGraw-Hill, Multimedia Edition.

Turban, E., Volonino, L., Wood, G.,(2013),Information technology for management Advancing; Sustainable, Profitable,Business growth. 9 th edition, Wiley.

Vakola, M. \& Wilson, I.E.: (2004), The challenge of virtual organization: critical success factors in dealing with constant change. Team Performance Management. URL [http//:worldwidestatistics.com] 